\title{
Thermal characteristics of pure and substituted gel grown Gd-molybdate crystals
}

\author{
VINAY HANGLOO, K K BAMZAI, P N KOTRU* and M L KOUL ${ }^{\dagger}$ \\ Department of Physics \& Electronics, 'Department of Chemistry, University of Jammu, Jammu 180 006, India
}

MS received 17 February 2003; revised 4 August 2003

\begin{abstract}
Polycrystalline spherulitic crystals of pure Gd-heptamolybdate and single and twinned crystals of substituted Gd-Ba-molybdate were grown by using gel encapsulation technique. The thermal behaviour of these crystals was studied using the thermoanalytical techniques, which included TG, DTA and DSC. Thermal analysis suggests decomposition of the materials in one or more than one stages. Results obtained on application of TG based models viz. Horowitz-Metzger, Coats-Redfern and Piloyan-Novikova, are reported. According to the results of the kinetics of thermal decomposition, the random nucleation model is shown to be the one that is relevant to the decomposition of single rare earth $(\mathrm{Gd})$ containing material and contracting sphere to the decomposition of the substituted (Gd-Ba) one. The kinetic parameters viz. the order of reaction, frequency factor and energy of activation using above-mentioned models, are computed and shown to bear reasonably good agreement.
\end{abstract}

Keywords. Gel growth; Gd and Gd-Ba-molybdate; thermal behaviour; solid state reaction kinetics.

\section{Introduction}

Rare earth molybdates are interesting materials as they find wide technological applications on account of their ferroelectric, piezoelectric, laser, ferroelastic and other important properties. Growth of such crystals by techniques involving high temperatures and their characterization has been reported (Brixner 1973). This laboratory has already reported the growth of some rare earth heptamolybdate crystals bearing a general formula, $\mathrm{R}_{2} \mathrm{Mo}_{7} \mathrm{O}_{24}$, by using an inexpensive and simple technique of growth called gel encapsulation technique (Bhat and Kotru 1994a,b). The authors have reported the growth of Gdheptamolybdate crystals. It was thought worthwhile to investigate the thermal behaviour of these materials in greater detail as IR spectroscopy results suggest water of hydration present in the pure Gd-heptamolybdate only but not the ones substituted by barium. This paper reports the results of thermal characteristics of the pure $\mathrm{Gd}$ heptamolybdate and substituted Gd-Ba-molybdate crystals grown by gel encapsulation technique.

\section{Experimental}

With the help of single gel single tube (SGST) technique and using the system of $\mathrm{RCl}_{3}-\left(\mathrm{NH}_{4}\right)_{6} \mathrm{Mo}_{7} \mathrm{O}_{24}-\mathrm{NH}_{4} \mathrm{NO}_{3}-$ $\mathrm{HNO}_{3}-\mathrm{Na}_{2} \mathrm{SiO}_{3}$ (where $\mathrm{R}=\mathrm{Gd}$, $\mathrm{Gd}: \mathrm{Ba}$ ), crystal growth of pure $\mathrm{Gd}$ and mixed $\mathrm{Gd}-\mathrm{Ba}-$ molybdates was achieved.

\footnotetext{
*Author for correspondence
}

Using different physico-chemical techniques viz. EDAX, $\mathrm{XRD}$, IR and thermal analysis, the stoichiometry of the grown crystals was established as $\mathrm{Gd}_{2} \mathrm{Mo}_{7} \mathrm{O}_{24} \cdot 14 \cdot 5 \mathrm{H}_{2} \mathrm{O}$ for Gd-heptamolybdate and $\mathrm{Gd}_{2} \mathrm{Ba}_{24} \mathrm{Mo}_{42} \mathrm{O}_{153}$ for mixed $\mathrm{Gd}-$ Ba-molybdate. Thermal behaviour of these materials was investigated using TG, DTA and DSC. TG and DTA curves were recorded simultaneously on a thermal analyser over the temperature range from $25-1500^{\circ} \mathrm{C}$. A sample of $10 \mathrm{mg}$ was used and the recordings were carried out in $\mathrm{N}_{2}$ atmosphere at a heating rate of $10^{\circ} \mathrm{C} / \mathrm{min}$, chart speed of $20 \mathrm{~cm} / \mathrm{h}$ and flow rate of $50 \mathrm{ml} / \mathrm{min}$. The DSC measurements were carried out on a DSC thermal analyser (DSC60, Shimadzu make) over a temperature range from 25 $600^{\circ} \mathrm{C}$. Sample of $3.930 \mathrm{mg}$ (in case of pure Gd-heptamolybdate) and $3.241 \mathrm{mg}$ (in case of mixed Gd-Ba-molybdate) were used and the recordings were carried out in $\mathrm{N}_{2}$ atmosphere at a flow rate of $30 \mathrm{ml} / \mathrm{min}$ and heating rate of $10^{\circ} \mathrm{C} / \mathrm{min}$.

\section{Results and discussion}

From the total weight loss suffered in the first decomposition step as given by TG curve of pure Gd-heptamolybdate, the number of water molecules associated with the material is calculated. The material is seen to be associated with 14.5 water molecules. In contrast to this, substituted Gd-Ba-molybdate does not carry water of hydration. This fact is also supported by IR spectroscopy carried out on the sample. Figure 1 represents the simultaneously recorded TG/DTA curves for pure Gd-heptamolybdate crystals. One can clearly see from the TG curve 
that the material starts decomposing at about $42^{\circ} \mathrm{C}$. The decomposition process of the sample does not get completed even in two steps as is evident from the TG curve and shows that the decomposition continues even after reaching the maximum temperature of $1500^{\circ} \mathrm{C}$. During the entire decomposition process pure Gd-heptamolybdate loses the entire associated 14.5 water molecules along with one $\mathrm{MoO}_{3}$ molecule. A number of compounds crystallizing with water of hydration and losing water from somewhere at $40^{\circ} \mathrm{C}$ onwards has been reported (Kotru et al 1986a,b,c; 1987a).

In the present case the first step of decomposition of Gd-heptamolybdate, which starts at $42^{\circ} \mathrm{C}$ is completed at $760^{\circ} \mathrm{C}$, resulting in a weight loss of $16 \%$ of the total weight of the material taken. In this step elimination of all the 14.5 water molecules takes place. At this stage the material gets reduced to anhydrous $\mathrm{Gd}_{2} \mathrm{Mo}_{7} \mathrm{O}_{24}$. On further heating, the sample remains stable for a temperature interval of $760-870^{\circ} \mathrm{C}$. After this the second decomposition step starts which seems to continue even after reach-

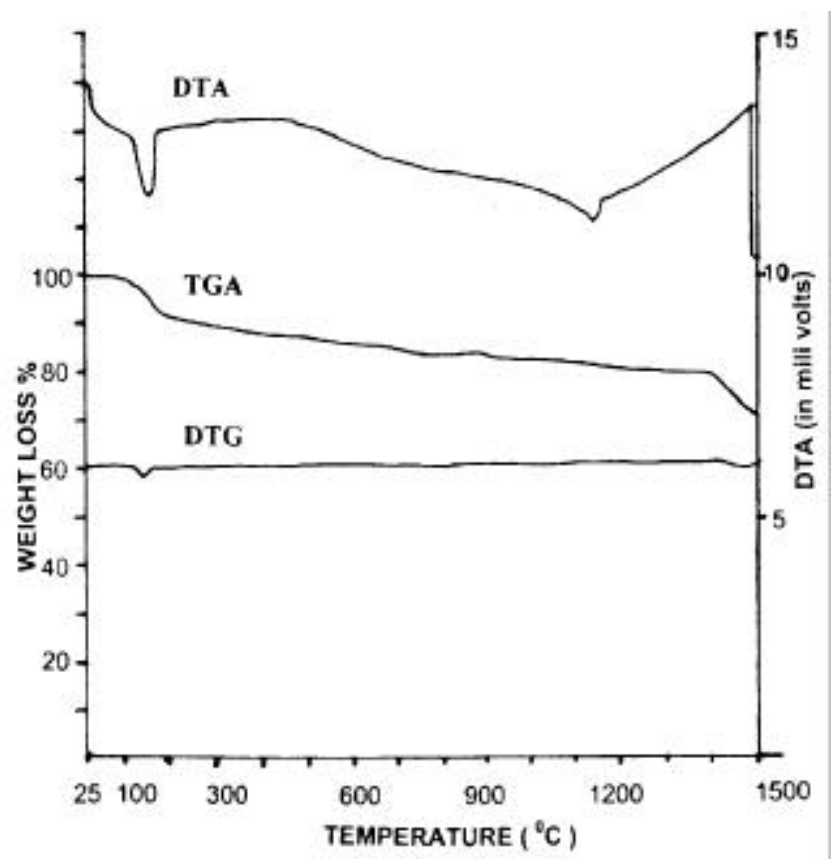

Figure 1. DTA/TGA/DTG curves for pure $\mathrm{Gd}_{2} \mathrm{Mo}_{7} \mathrm{O}_{24} 14 \cdot 5 \mathrm{H}_{2} \mathrm{O}$. ing the maximum temperature of about $1500^{\circ} \mathrm{C}$. In this temperature interval $\left(870-1500^{\circ} \mathrm{C}\right)$ a total weight loss of $28 \%$ is observed. The weight loss in the second step (though not a complete step) corresponds to a further removal of one $\mathrm{MoO}_{3}$ molecule. In this way the material finally gets reduced to anhydrous $\mathrm{Gd}_{2} \mathrm{Mo}_{6} \mathrm{O}_{21}$. Table 1 gives the whole summary of decomposition process of $\mathrm{Gd}_{2} \mathrm{Mo}_{7} \mathrm{O}_{24} 14 \cdot 5 \mathrm{H}_{2} \mathrm{O}$. It can be seen that the calculated weight losses are in close proximity with the observed values.

DTA curve of figure 1 showing a well-marked endothermic downward peak between $40^{\circ} \mathrm{C}$ and $300^{\circ} \mathrm{C}$, with a sharp feature at about $150^{\circ} \mathrm{C}$, corresponds to the first step of TG curve. If one goes for critical analysis of the TG curve of figure 1 , one can observe a weight loss of $16 \%$ taking place in this step and this loss is not ending up at $200^{\circ} \mathrm{C}$ but even beyond this temperature. From the graph one can observe that the gradual weight loss in the sample is taking place even beyond $200^{\circ} \mathrm{C}$ and finally ends up at $\sim 760^{\circ} \mathrm{C}$. The second endothermic peak in DTA (460$1500^{\circ} \mathrm{C}$ ) is very well supported by TG curve, showing the weight loss (though not sudden but gradual), actually starting from $870^{\circ} \mathrm{C}$ and lasting up to $1500^{\circ} \mathrm{C}$ or beyond. In this temperature range we can observe an endothermic peak. The endothermic peak around $1200^{\circ} \mathrm{C}$ in the DTA curve, which has a sharp feature at around $1150^{\circ} \mathrm{C}$, suggests some structural changes besides weight loss taking place in the sample. The existence of this peak can be explained in terms of energy requirements. The energy of an endothermic peak does not necessarily depend only on the amount of water lost on dehydration. It also depends upon the structural factors. Further at a temperature of $1400^{\circ} \mathrm{C}$ one can observe an abrupt weight loss taking place in the sample, which is reflected in the TG curve. In the DTA curve one can observe an endothermic peak (though not completed one) corresponding to the loss of weight. Since the instrument cannot go beyond $1500^{\circ} \mathrm{C}$, complete endotherm could not be recorded.

Figure 2 shows the simultaneously recorded TG/DTA curves of substituted $\mathrm{Gd}-\mathrm{Ba}$-molybdate crystals. It is quite clear from the TG curve that the material starts decomposing at about $376^{\circ} \mathrm{C}$. The material suffers complete decomposition in a single step only till it reaches a temperature of $1204^{\circ} \mathrm{C}$ beyond which the material remains stable even though the material is continuously heated.

Table 1. Results of thermal decomposition of $\mathrm{Gd}_{2} \mathrm{Mo}_{7} \mathrm{O}_{24} 14 \cdot 5 \mathrm{H}_{2} \mathrm{O}$.

\begin{tabular}{lcccc}
\hline & & & \multicolumn{2}{c}{ Total weight loss (\%) } \\
\cline { 3 - 5 } Step & Temperature $\left({ }^{\circ} \mathrm{C}\right)$ & Decomposition step & Observed & Calculated \\
\hline I & $42-760^{\circ} \mathrm{C}$ & $\mathrm{Gd}_{2} \mathrm{Mo}_{7} \mathrm{O}_{24} \cdot 14 \cdot 5 \mathrm{H}_{2} \mathrm{O} \stackrel{-14 \cdot 5 \mathrm{H}_{2} \mathrm{O}}{\longrightarrow} \mathrm{Gd}_{2} \mathrm{Mo}_{7} \mathrm{O}_{24}$ & $16 \cdot 00$ & 15.99 \\
$\mathrm{II}$ & $870-1500^{\circ} \mathrm{C}$ & $\mathrm{Gd}_{2} \mathrm{Mo}_{7} \mathrm{O}_{24} \stackrel{-\mathrm{MoO}_{3} \longrightarrow \mathrm{Gd}_{2} \mathrm{Mo}_{6} \mathrm{O}_{21}}{\longrightarrow}$ & $12 \cdot 00$ & $10 \cdot 51$ \\
\hline
\end{tabular}


After carrying out the critical analysis of TG curve shown in figure 2 one can observe gradual weight loss taking place even beyond $700^{\circ} \mathrm{C}$ and lasting up to $\sim 1204^{\circ} \mathrm{C}$. Up to the end of this step a total weight loss of $40 \%$ is observed. It is presumed that this weight loss is due to the loss of $42 \mathrm{MoO}_{3}$ molecules and the material finally gets reduced to $\mathrm{Gd}_{2} \mathrm{O}_{3} \cdot 24 \mathrm{BaO}$ or $\mathrm{Gd}_{2} \mathrm{Ba}_{24} \mathrm{O}_{27}$. Table 2 gives the summary of decomposition process of $\mathrm{Gd}_{2} \mathrm{Ba}_{24} \mathrm{Mo}_{42} \mathrm{O}_{153}$. From the values given in the table it can be seen that the calculated weight loss is in good agreement with the observed values.

DTA curve in figure 2 shows a defused endothermic peak between $376^{\circ} \mathrm{C}$ and $1475^{\circ} \mathrm{C}$, which corresponds to the only decomposition step of TG curve. The first endotherm peak in DTA of figure 2 between 25 and $250^{\circ} \mathrm{C}$ is not of any significance so far as the intrinsic characteristics of the material are concerned. As in this temperature range there is no weight loss taking place in the sample as reflected by the TG curve. The DSC curve is also supporting this insignificance. From the DTA curve it is clear that the said peak in the DTA is so defused that it hardly makes any sense. The second endotherm peak of the DTA, which starts at about $376^{\circ} \mathrm{C}$ and lasts up to $\sim 1475^{\circ} \mathrm{C}$ is in

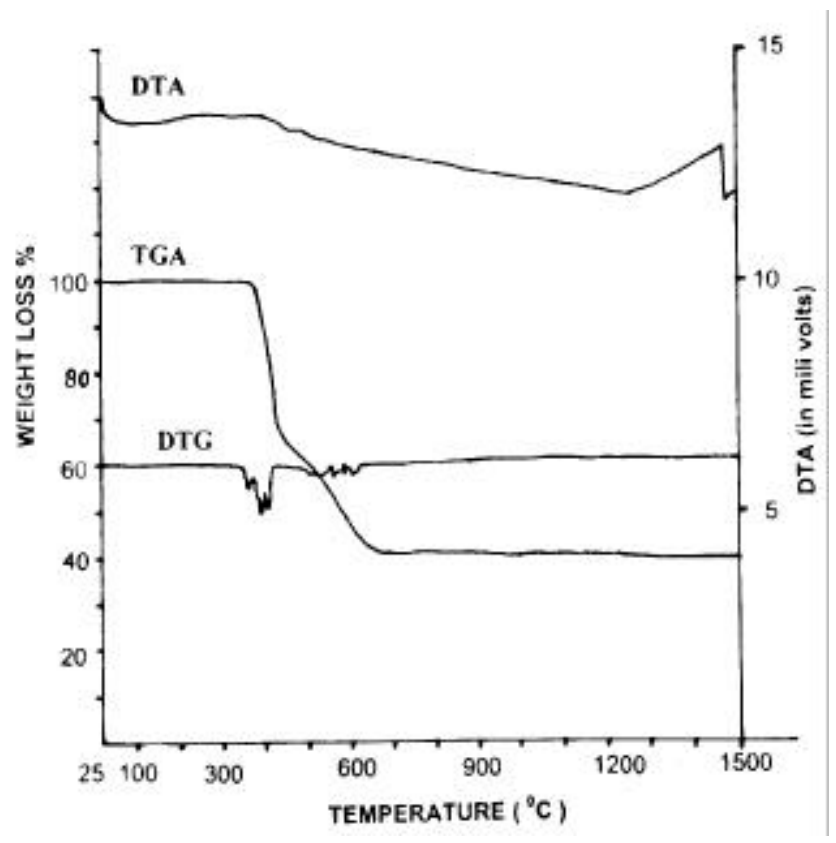

Figure 2. DTA/TGA/DTG curves for mixed $\mathrm{Gd}_{2} \mathrm{Ba}_{24} \mathrm{Mo}_{42} \mathrm{O}_{153}$. correspondence with the weight loss of $60 \%$ suffered by the sample in single step as reflected by the TG curve of the same figure. The DSC curve of the same sample shown in figure 4 , shows a well marked endotherm at about $415^{\circ} \mathrm{C}$, which falls within the temperature range of $376-1475^{\circ} \mathrm{C}$. However, due to the limitations of DSC any changes beyond $600^{\circ} \mathrm{C}$ cannot be recorded.

Figure 3 shows the DSC plot of pure Gd-heptamolybdate crystals. TG curve (figure 1 ) very much shows the loss of all $14.5 \mathrm{H}_{2} \mathrm{O}$ molecules in the first step of decomposition, which starts at around $42^{\circ} \mathrm{C}$ and lasts up to $\sim 760^{\circ} \mathrm{C}$. In DSC curve (figure 3) the loss is also reflected within the same temperature range. It is limitation on the part of the DSC instrument, which cannot go beyond $600^{\circ} \mathrm{C}$. The loss of water, which is very prominent in TG curve at around $150^{\circ} \mathrm{C}$, is supported by the first endotherm (very sharp as compared to second one) of DSC at around $141^{\circ} \mathrm{C}$ and the further loss of water beyond $150^{\circ} \mathrm{C}$, though gradual, is supported by the second endotherm of DSC curve (slightly defused than the first one), which we get at around $460^{\circ} \mathrm{C}$. TG curve is reflective of the fact that gradual loss of water is taking place in the sample at around $460^{\circ} \mathrm{C}$, which though is not so apparent from the graph as it should have been but critical examination does reveal it. The sharp downward endothermic peak at about $142^{\circ} \mathrm{C}$ corresponds to the loss of maximum number of water molecules in the first step. The other endothermic peak at about $460^{\circ} \mathrm{C}$, though defused in comparison to the first endothermic peak, is attributed to the further loss of water molecules present in the sample under investigation. The enthalpy values corresponding to first and second endothermic peaks are $-596.55 \mathrm{~mJ}$ (or $-151.79 \mathrm{~J} / \mathrm{g}$ ) and $-1.12 \mathrm{~J}$ (or $-284.78 \mathrm{~J} / \mathrm{g}$ ), respectively.

Figure 4 is the representative DSC plot of mixed GdBa-molybdate crystals. The DSC curve of the same sample shown in figure 4 , shows a well-marked endotherm at about $415^{\circ} \mathrm{C}$, which falls within the temperature range of $376-1475^{\circ} \mathrm{C}$. However, due to the limitations of DSC, any changes beyond $600^{\circ} \mathrm{C}$ cannot be recorded. From the DSC plot one can observe the downward trend in the curve right from the start, which is attributed to the loss of some adsorbed material from the material under investigation. The endothermic peak is obtained at a temperature of about $415^{\circ} \mathrm{C}$ with an enthalpy of $-65.25 \mathrm{~mJ}$ (or $-20.13 \mathrm{~J} / \mathrm{g}$ ). The only endothermic peak in the DSC plot suggests the loss of all $42 \mathrm{MoO}_{3}$ molecules besides some structural changes that may be occurring in the sample under study.

Table 2. Results of thermal decomposition of $\mathrm{Gd}_{2} \mathrm{Ba}_{24} \mathrm{Mo}_{42} \mathrm{O}_{153}$.

\begin{tabular}{lcccc}
\hline & & \multicolumn{2}{c}{ Total weight loss (\%) } \\
\cline { 3 - 4 } Step & Temperature $\left({ }^{\circ} \mathrm{C}\right)$ & Decomposition step & Observed & Calculated \\
\hline $\mathrm{I}$ & $376-1204^{\circ} \mathrm{C}$ & $\mathrm{Gd}_{2} \mathrm{Ba}_{24} \mathrm{Mo}_{42} \mathrm{O}_{153} \stackrel{-42 \mathrm{MoO}_{3}}{\longrightarrow} \mathrm{Gd}_{2} \mathrm{O}_{3} 24 \mathrm{BaO}$ & 60.00 & 59.92 \\
\hline
\end{tabular}


The above results suggest that pure Gd-heptamolybdate containing 14.5 water molecules loses all the associated water molecules along with one $\mathrm{MoO}_{3}$ molecule and is rendered anhydrous, bearing composition $\mathrm{Gd}_{2} \mathrm{Mo}_{6} \mathrm{O}_{21}$, on heating within a temperature range of $42-1500^{\circ} \mathrm{C}$. On the other hand, mixed $\mathrm{Gd}-\mathrm{Ba}$-molybdate is reduced to $\mathrm{Gd}_{2} \mathrm{O}_{3} \cdot 24 \mathrm{BaO}$ after losing all the $42 \mathrm{MoO}_{3}$ molecules on heating within a temperature range of $376-1204^{\circ} \mathrm{C}$.

For the study of kinetics of solid state decomposition of the compounds, three equations viz. Horowitz-Metzger (1963), Piloyan-Novikova (1966) and Coats-Redfern (1964), were used for calculating the energy of activation $\left(E_{\mathrm{a}}\right)$, order of reaction $(n)$ and frequency factor $(Z)$. Only the first stage of decomposition was used for these calculations, as in the subsequent stages the sample characteristics cannot be controlled. It may be noted that the application of methods based on TG have yielded considerable information regarding some rare earth containing tartrates (Kotru et al 1986a,c,d; 1987a,b; Bhat 1988; Jain 1991; Mansotra et al 1991).

On application of $\mathrm{H}-\mathrm{M}$ relation a good linear fit is observed for $g(\alpha)=-\ln (1-\alpha)$, for pure Gd-heptamolyb-

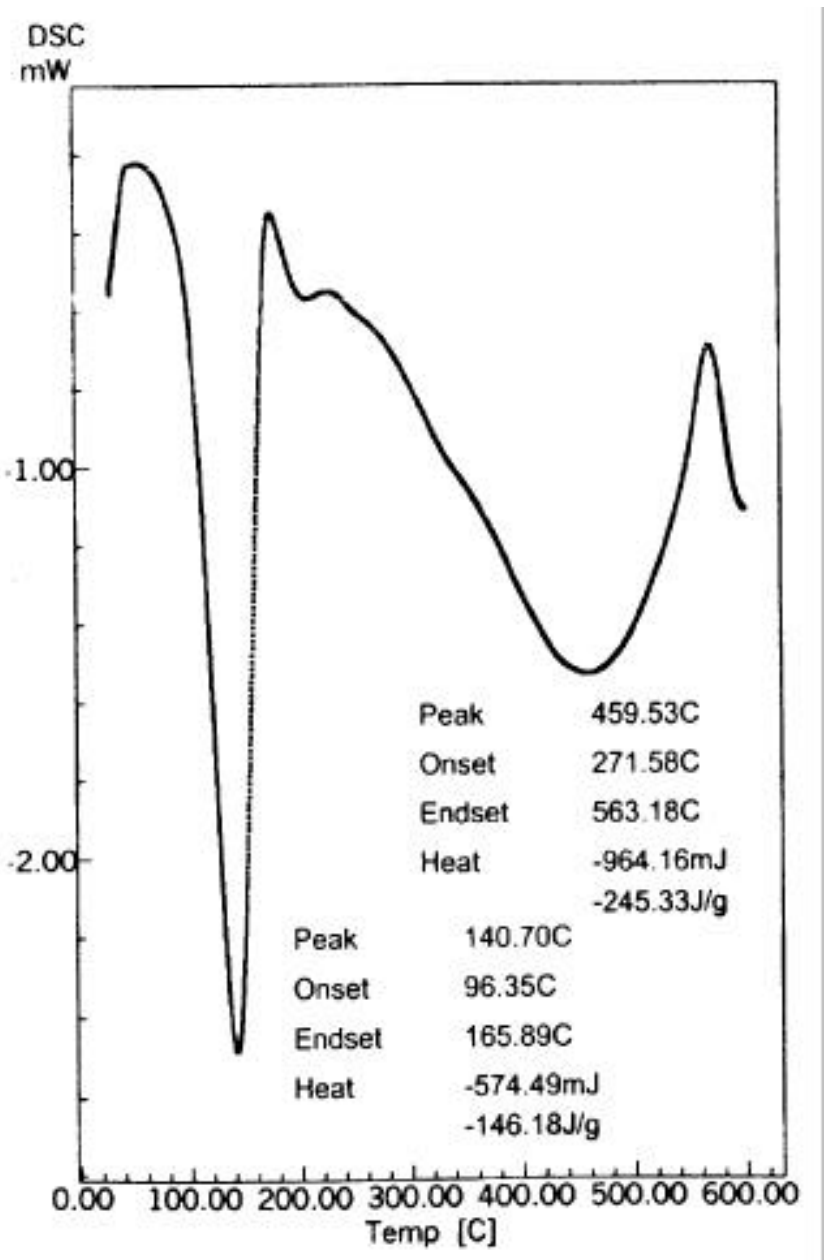

Figure 3. DSC plot of pure $\mathrm{Gd}_{2} \mathrm{Mo}_{7} \mathrm{O}_{24} 14 \cdot 5 \mathrm{H}_{2} \mathrm{O}$. date as is shown in figure 5, thereby suggesting the random nucleation model as the appropriate one (Wiedmann 1970) for the mechanism of decomposition of the sample under consideration. The order of reaction and the activation energy from the relation is estimated as $n=1$ and $E_{\mathrm{a}}=49.231 \mathrm{~kJ} / \mathrm{mol}$, respectively. The $\mathrm{C}-\mathrm{R}$ relation also gives the best linear plot for $g(\alpha)=-\ln (1-\alpha)$, as illustrated in figure 6 , thus confirming that the same mechanism of decomposition viz. random nucleation, is applicable as is also suggested by $\mathrm{H}-\mathrm{M}$ relation discussed above. The values of order of reaction $(n)$, frequency factor $(Z)$ and energy of activation $\left(E_{\mathrm{a}}\right)$ are calculated as $n=1, Z=2 \cdot 32 \times$ $10^{2} / \mathrm{min}$ and $E_{\mathrm{a}}=30.620 \mathrm{~kJ} / \mathrm{mol}$, respectively. The P-N relation yields a linear plot as shown in figure 7 . The values of frequency factor and energy of activation are computed as $Z=1.89 \times 10^{2} / \mathrm{min}$ and $E_{\mathrm{a}}=28.075 \mathrm{~kJ} / \mathrm{mol}$, respectively. Table 3 gives the compiled data obtained for various kinetic parameters as discussed above, applying the equations of $\mathrm{H}-\mathrm{M}, \mathrm{C}-\mathrm{R}$ and $\mathrm{P}-\mathrm{N}$, using the first step of TG only. From the data, it is clear that the values

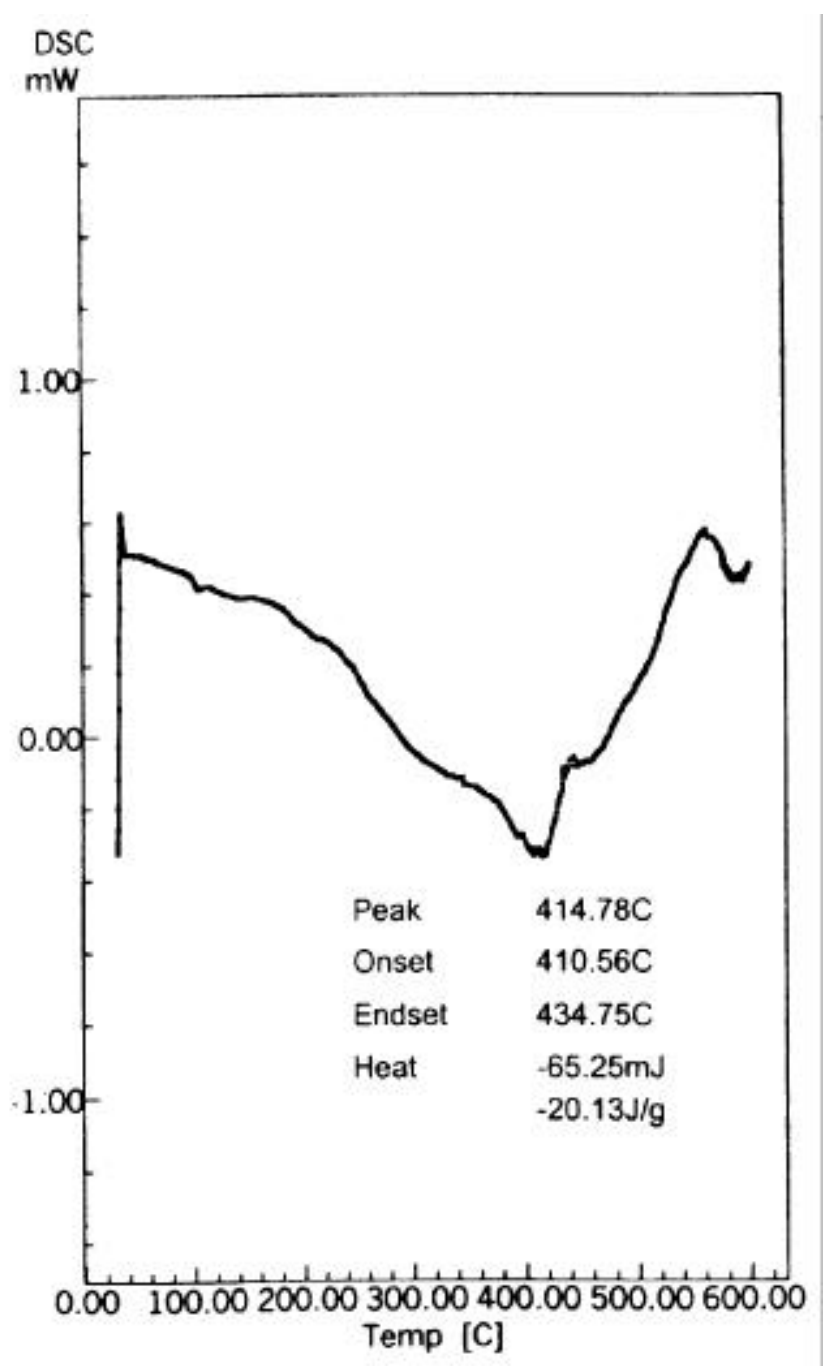

Figure 4. DSC plot of mixed $\mathrm{Gd}_{2} \mathrm{Ba}_{24} \mathrm{Mo}_{42} \mathrm{O}_{153}$. 
of kinetic parameters obtained from the relevant equations are in reasonably good agreement.

In the case of mixed Gd-Ba-molybdate crystals also the application of $\mathrm{H}-\mathrm{M}$ relation leads to a good linear fit as shown in figure 8 , thereby suggesting the contracting sphere model as the appropriate one for the decomposition of the sample under consideration. The order of reaction and the activation energy from the relation is estimated as $n=2 / 3$ and $E_{\mathrm{a}}=170 \cdot 246 \mathrm{~kJ} / \mathrm{mol}$, respectively. The C-R relation also gives the best linear plot for $g(\alpha)=-\ln (1-\alpha)$, as illustrated in figure 9 , thus confirming that the same mechanism of decomposition as suggested by $\mathrm{H}-\mathrm{M}$ relation viz. contracting sphere, is applicable. The values of order of reaction $(n)$, frequency factor $(Z)$ and energy of activation $\left(E_{\mathrm{a}}\right)$ are calculated as $n=2 / 3, Z=0.713 \times 10^{3} / \mathrm{min}$ and $E_{\mathrm{a}}=149.275 \mathrm{~kJ} / \mathrm{mol}$, respectively. The P-N relation yields a linear plot as shown in figure 10. The values of frequency factor and energy of activation are computed as

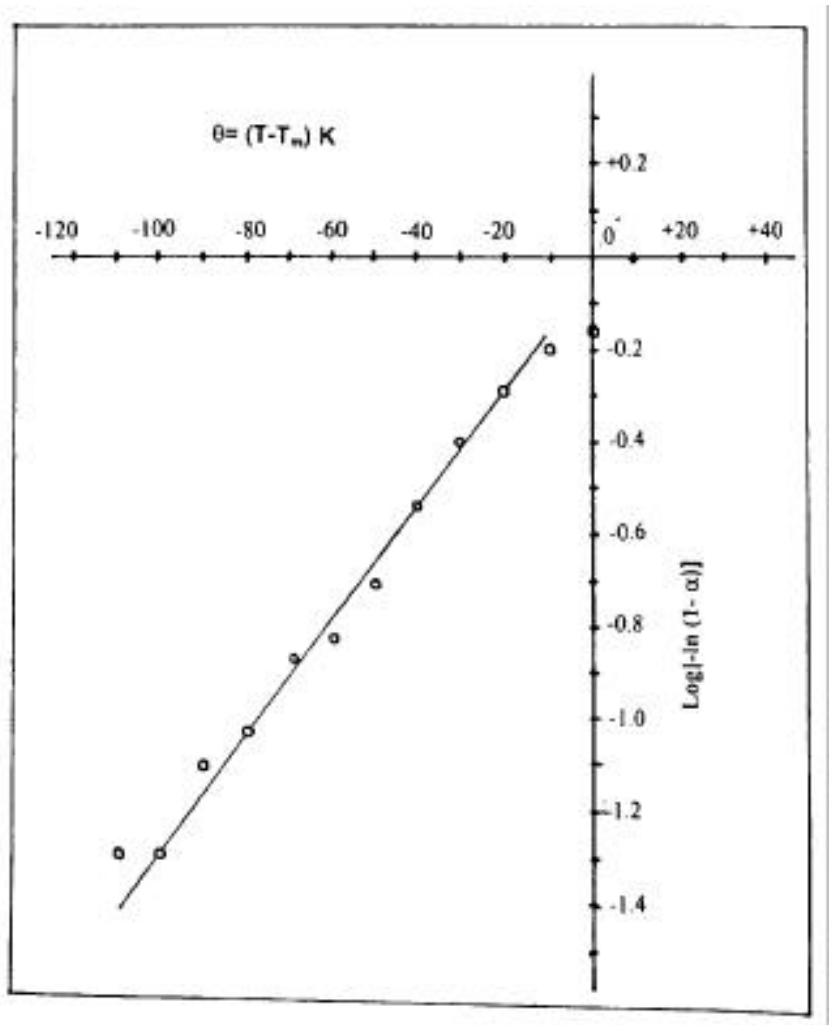

Figure 5. Horowitz-Metzger plot for pure $\mathrm{Gd}_{2} \mathrm{Mo}_{7} \mathrm{O}_{24} 14 \cdot 5 \mathrm{H}_{2} \mathrm{O}$.

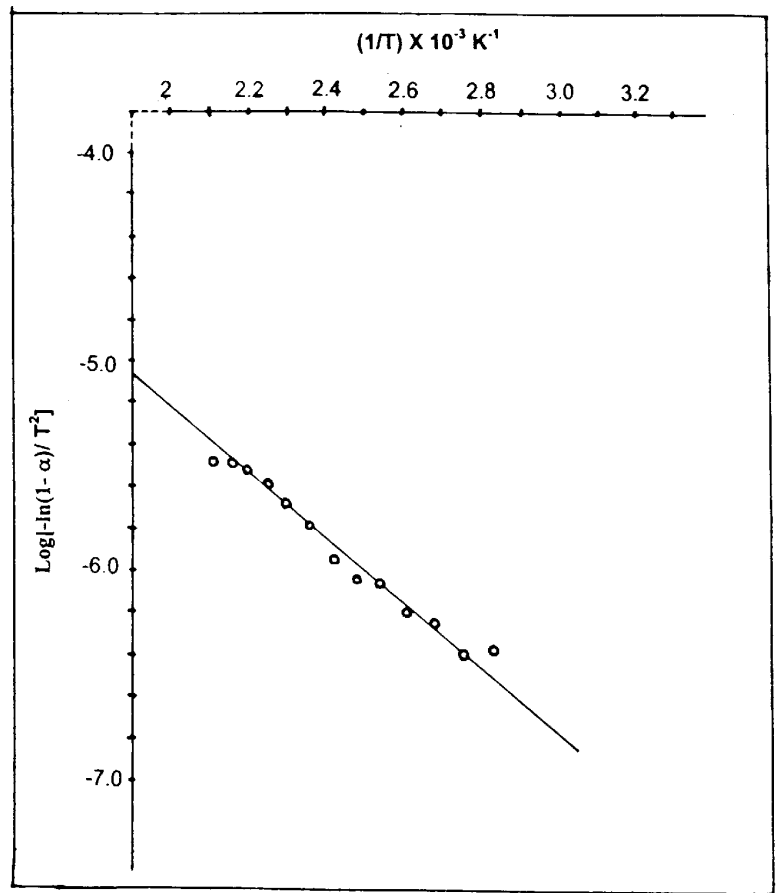

Figure 6. Coats-Redfern plot for pure $\mathrm{Gd}_{2} \mathrm{Mo}_{7} \mathrm{O}_{24} 14 \cdot 5 \mathrm{H}_{2} \mathrm{O}$.

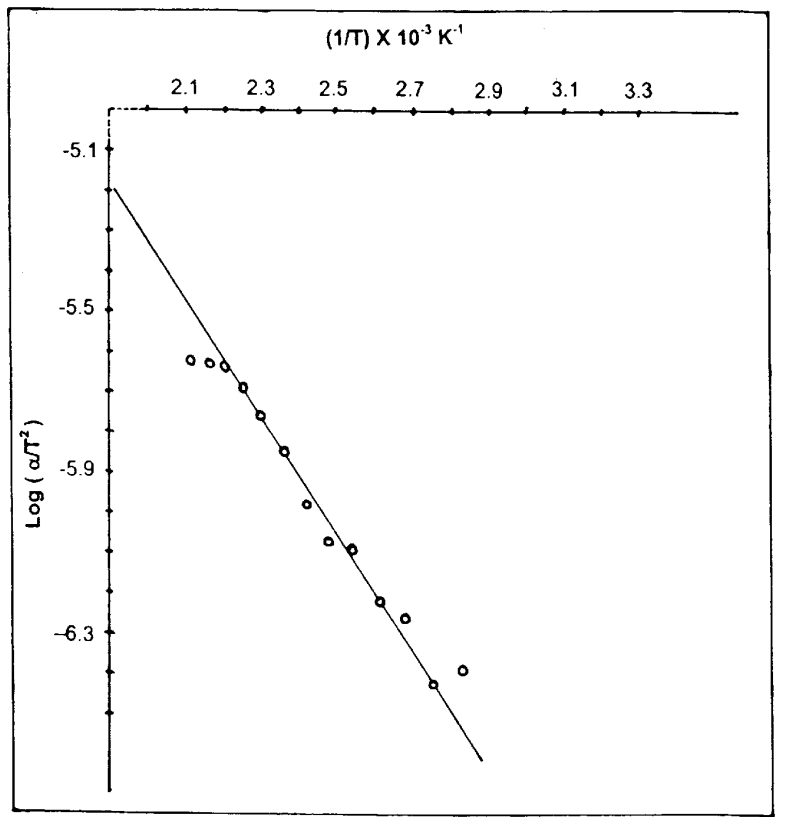

Figure 7. Piloyan-Novikova plot for pure $\mathrm{Gd}_{2} \mathrm{Mo}_{7} \mathrm{O}_{24} 14 \cdot 5 \mathrm{H}_{2} \mathrm{O}$.

Table 3. Energy of activation, order of reaction and frequency factor calculated using Ist step of TG of mixed $\mathrm{Gd}_{2} \mathrm{Mo}_{7} \mathrm{O}_{24} \cdot 14 \cdot 5 \mathrm{H}_{2} \mathrm{O}$.

\begin{tabular}{lcccc}
\hline Equation used & $\begin{array}{c}\text { Order of } \\
\text { reaction }(n)\end{array}$ & $\begin{array}{c}\text { Model applicable } \\
\text { to solid state reactions }\end{array}$ & $\begin{array}{c}\text { Frequency factor } \\
(Z) / \mathrm{min}\end{array}$ & $\begin{array}{c}\text { Energy of } \\
\text { activation } \\
\left(E_{\mathrm{a}}\right)(\mathrm{kJ} / \mathrm{mol})\end{array}$ \\
\hline Piloyan-Novikova & - & Random nucleation & $1 \cdot 89 \times 10^{2}$ & $28 \cdot 075$ \\
Horowitz-Metzger & 1 & Random nucleation & - & $49 \cdot 231$ \\
Coats-Redfern & 1 & Random nucleation & $2 \cdot 32 \times 10^{2}$ & $30 \cdot 620$ \\
\hline
\end{tabular}


$Z=21.189 \times 10^{3} / \mathrm{min}$ and $E_{\mathrm{a}}=138.214 \mathrm{~kJ} / \mathrm{mol}$, respectively. Table 4 gives the compiled data obtained for various kinetic parameters as discussed above, applying the equations of $\mathrm{H}-\mathrm{M}, \mathrm{C}-\mathrm{R}$ and $\mathrm{P}-\mathrm{N}$ and using the first step of TG. From the data, it is clear that the values of kinetic parameters obtained from the relevant equations are in reasonably good agreement.

\section{Conclusions}

From the above, the following conclusions are drawn:

(I) Thermogravimetric methods have established that the gel grown pure Gd-heptamolybdate crystals are associated with 14.5 water molecules, the exact stoichiometric composition being $\mathrm{Gd}_{2} \mathrm{Mo}_{7} \mathrm{O}_{24} 14 \cdot 5 \mathrm{H}_{2} \mathrm{O}$. Mixed crystals of $\mathrm{Gd}-\mathrm{Ba}-$ molybdate crystals do not carry any such water of hydration.

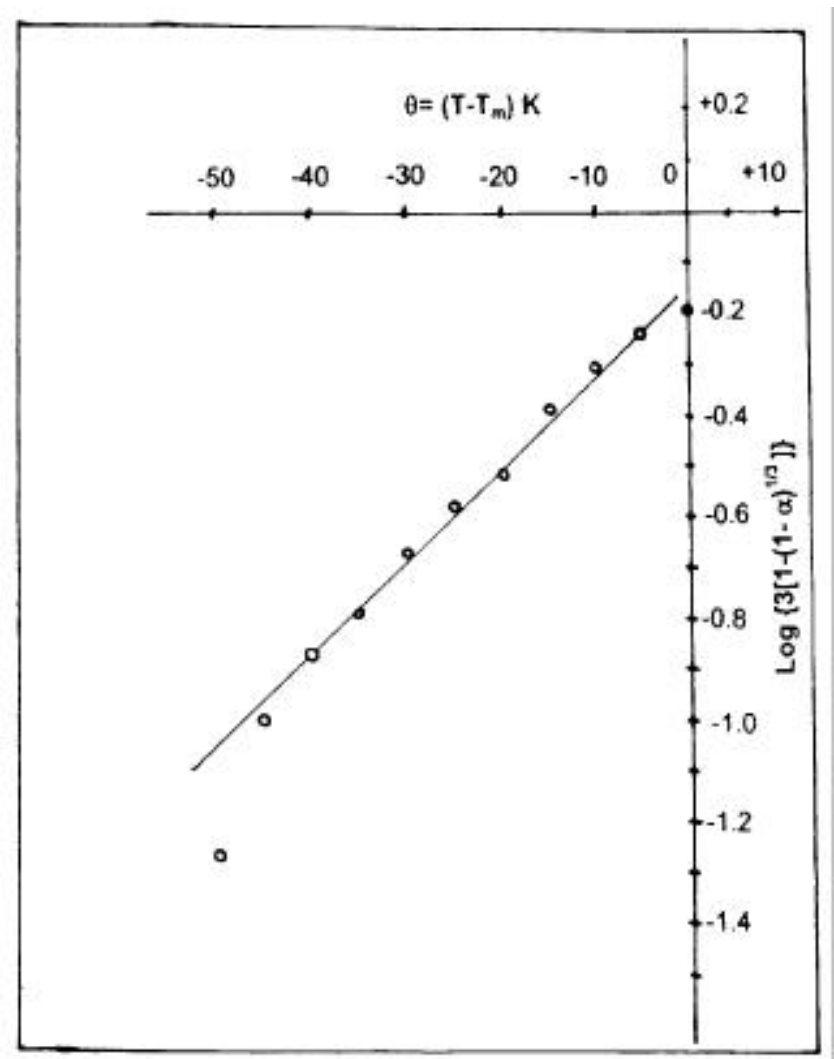

Figure 8. Horowitz-Metzger plot for mixed $\mathrm{Gd}_{2} \mathrm{Ba}_{24} \mathrm{Mo}_{42} \mathrm{O}_{153}$.

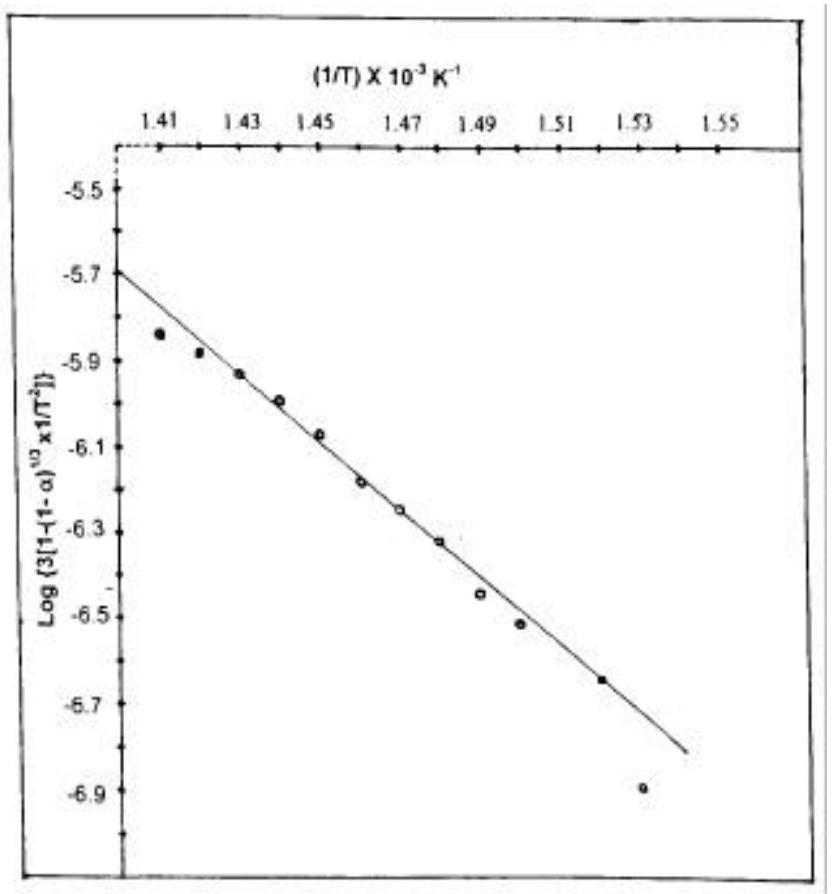

Figure 9. Coats-Redfern plot for mixed $\mathrm{Gd}_{2} \mathrm{Ba}_{24} \mathrm{Mo}_{42} \mathrm{O}_{153}$.

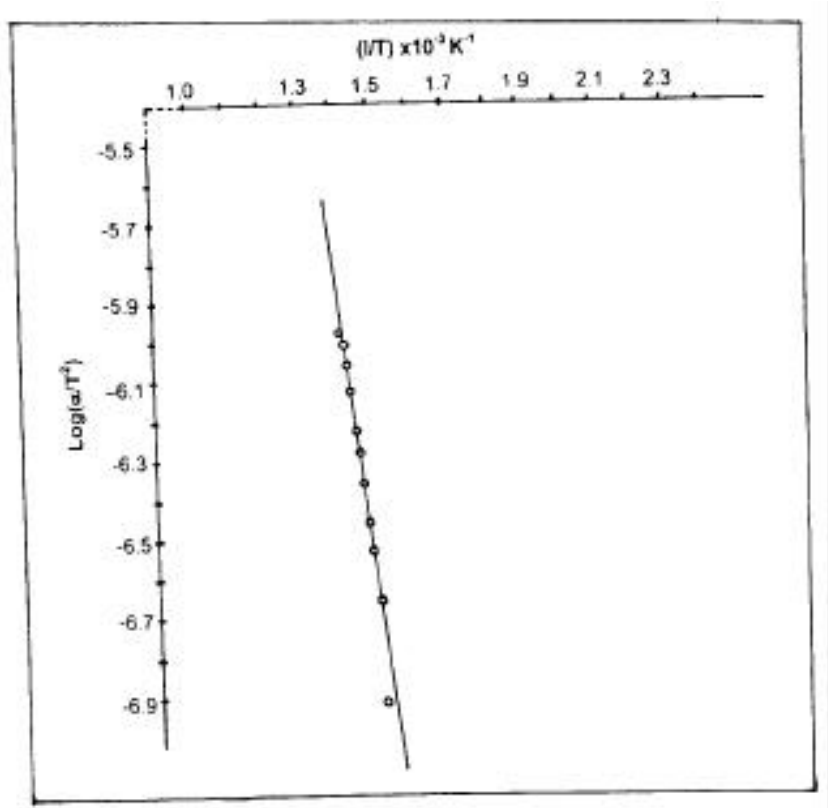

Figure 10. Piloyan-Novikova plot for mixed $\mathrm{Gd}_{2} \mathrm{Ba}_{24} \mathrm{Mo}_{42} \mathrm{O}_{153}$.

Table 4. Energy of activation, order of reaction and frequency factor calculated using Ist step of TG of pure $\mathrm{Gd}_{2} \mathrm{Ba}_{24} \mathrm{Mo}_{42} \mathrm{O}_{153}$.

\begin{tabular}{lclcc}
\hline Equation used & $\begin{array}{c}\text { Order of } \\
\text { reaction }(n)\end{array}$ & $\begin{array}{c}\text { Model applicable to } \\
\text { solid state reactions }\end{array}$ & $\begin{array}{c}\text { Frequency factor } \\
(Z) / \text { min }\end{array}$ & $\begin{array}{c}\text { Energy of activation } \\
\left(E_{\mathrm{a}}\right)(\mathrm{kJ} / \mathrm{mol})\end{array}$ \\
\hline Piloyan-Novikova & - & Contracting sphere & $21 \cdot 189 \times 10^{3}$ & 138.214 \\
Horowitz-Metzger & $2 / 3$ & Contracting sphere & - & $170 \cdot 246$ \\
Coats-Redfern & $2 / 3$ & Contracting sphere & $0.713 \times 10^{3}$ & $149 \cdot 275$ \\
\hline
\end{tabular}


(II) The thermal behaviour suggests that the pure Gdheptamolybdate decomposes at moderate temperatures i.e. $42^{\circ} \mathrm{C}$ and continues decomposing by ejecting all 14.5 water molecules alongwith one $\mathrm{MoO}_{3}$ molecule in two steps (one complete and the other incomplete), up to a temperature of $1500^{\circ} \mathrm{C}$. The decomposition of the pure material leads to formation of anhydrous Gd-molybdate of the type, $\mathrm{Gd}_{2} \mathrm{Mo}_{6} \mathrm{O}_{21}$. In case of substituted $\mathrm{Gd}-\mathrm{Ba}$ molybdate the thermal behaviour suggests the loss of $42 \mathrm{MoO}_{3}$ molecules in single step when it is heated up to a temperature of $1500^{\circ} \mathrm{C}$ reducing the original material to $\mathrm{Gd}_{2} \mathrm{O}_{3} 24 \mathrm{BaO}$.

(III) DTA and DSC curves also indicate that there may be some physical transformations (besides mass changes associated with loss of water in case of pure Gd-heptamolybdate) in case of pure and substituted Gd-Ba-molybdate crystals.

(IV) Application of $\mathrm{H}-\mathrm{M}$ and $\mathrm{C}-\mathrm{R}$ relations suggest random nucleation model as the appropriate one for the decomposition of pure Gd-heptamolybdate whereas $\mathrm{H}-\mathrm{M}$ and $\mathrm{C}-\mathrm{R}$ relations suggest contracting sphere model as the appropriate one for the decomposition of substituted Gd-Ba-molybdate crystals.

(V) The kinetic parameters viz. order of reaction $(n)$, frequency factor $(Z)$ and energy of activation $\left(E_{\mathrm{a}}\right)$, obtained using various equations based on $\mathrm{TG}$ are in reasonably good agreement in case of both pure and mixed Gd-Bamolybdate crystals.

\section{Acknowledgements}

The corresponding author is thankful to the CSIR, New Delhi, for support under 'Emeritus Scientist Scheme'.

\section{References}

Bhat S and Kotru P N 1994a Mater. Sci. \& Eng. B23 73

Bhat S and Kotru P N 1994b Cryst. Und Tech. 29325

Bhat S 1988 Studies on gel growth and characterization of neodymium paramolybdate crystals, M.Phil. Thesis, Jammu University, Jammu

Brixner L H 1973 J. Cryst. Growth 10297

Coats A W and Redfern J P 1964 Nature (GB) 20168

Horowitz H H and Metzger G 1963 Anal. Chem. (USA) 35 1464

Jain A 1991 Studies on low temperature solution grown rare earth $(Y, S m)$ tartrate and high temperature solution grown lanthanum borate crystals, $\mathrm{Ph} \mathrm{D}$ Thesis, Jammu University, Jammu

Kotru P N, Gupta N K, Raina K K and Sharma I B 1986a J. Mater. Sci. Lett. 2183

Kotru P N, Raina K K and Koul M L 1986b J. Mater. Sci. 21 3933

Kotru P N, Gupta N K, Raina K K and Koul M L 1986c Bull. Mater. Sci. Lett. 8547

Kotru P N, Raina K K and Koul M L 1986d J. Mater. Sci. 21 83

Kotru P N, Raina K K and Koul M L 1987a Indian J. Pure and Appl. Phys. 25220

Kotru P N, Raina K K and Koul M L 1987b J. Mater. Sci. Lett. 6711

Mansotra V, Raina K K, Kotru P N and Koul M L 1991 J. Mater. Sci. 266729

Piloyan G O and Novikova D S 1966 Russian J. Inorg. Chem. (USSR) 12313

Wiedmann 1970 Sestak in 'Thermal analysis' Proc. of the 3 rd international conference on thermal analysis 2 p. 24 